\title{
On the Kuroshio Branch in the Taiwan Strait During Wintertime
}

\author{
Wang Joe and ChING-SHENg ChERN \\ Institute of Oceanography, National Taiwan University, Taipei, Taiwan, China \\ (Received 10 February 1988; in revised form 26 May 1988; accepted 29 May 1988)
}

\begin{abstract}
Past investigations reported that warm and saline waters originating from the Kuroshio region occupied the northern South China Sea (NSCS) during wintertime. These waters were called a branch of the Kuroshio, and an offshoot of them was long believed to flow persistently along the west coast of Taiwan, contrary to the winter NE monsoon. However, these descriptions are not completely consistent with recent evidence. Field measurements in the eastern Taiwan Strait now available display a quasi-stationary oceanic front, whose alignment is roughly normal to the transverse of the strait, which separates the warmer, more saline water to the south, from the colder, fresher China coastal water in the north during most of the winter. This feature implies the further northward movement of southeasterly Kuroshio water having been stagnated by cold waters to the north of the front. Therefore, the intruded Kuroshio water driven by the NE monsoon tends to accumulate in the NSCS, and eventually establishes an anti-cyclonic warm core eddy there. The first event of the intrusion of warm waters from the eddy into, or even through, the Taiwan Strait usually appears when the NE wind weakens from a strong cold-air outbreak in winter or early spring. We believe the inception of the Kuroshio branch in the strait starts from such an intrusion event.
\end{abstract}

\section{INTRODUCTION}

Previous studies (Chu, 1963, 1971; FAN and YU, 1981; Fan, 1982, 1985) reported that the surface layer of the water of the Northern South China Sea (NSCS) in winter was dominated by the warm, saline waters from the Kuroshio region. These waters were called the Kuroshio branch, and an offshoot of them had long been believed to flow continuously northeastward along the west coast of Taiwan (CHU, 1963). The offshoot of the Kuroshio branch was summarized by CHU (1961) to be a rather permanent, year-round current, with its strongest flow occurring during the summer. This feature of flow pattern had been widely accepted by regional oceanographers for many years (e.g. WU, 1984). However, FAN and YU (1981) had questioned this pattern and had shown that the Kuroshio branch no longer existed during summertime, but rather the South China Sea (SCS) surface warm water flushed into the Taiwan Strait. Furthermore, the behavior of currents in the strait associated with the alternation of monsoon is not well-known, so that the seasonal transition of current pattern, especially, the inception and evolution of the Kuroshio branch in the strait, is a subject deserving further study.

Recently, hydrographic data and oceanic currents within the Taiwan Strait had been collected from extensive CTD surveys and by long-term moored instruments (WANG and Chern, 1985; Wang, Chern, Wu and Chern, 1986; Wang, Chern, Chen and Huang, 1987). These measurements show that the strait is dynamically quite complicated. In 


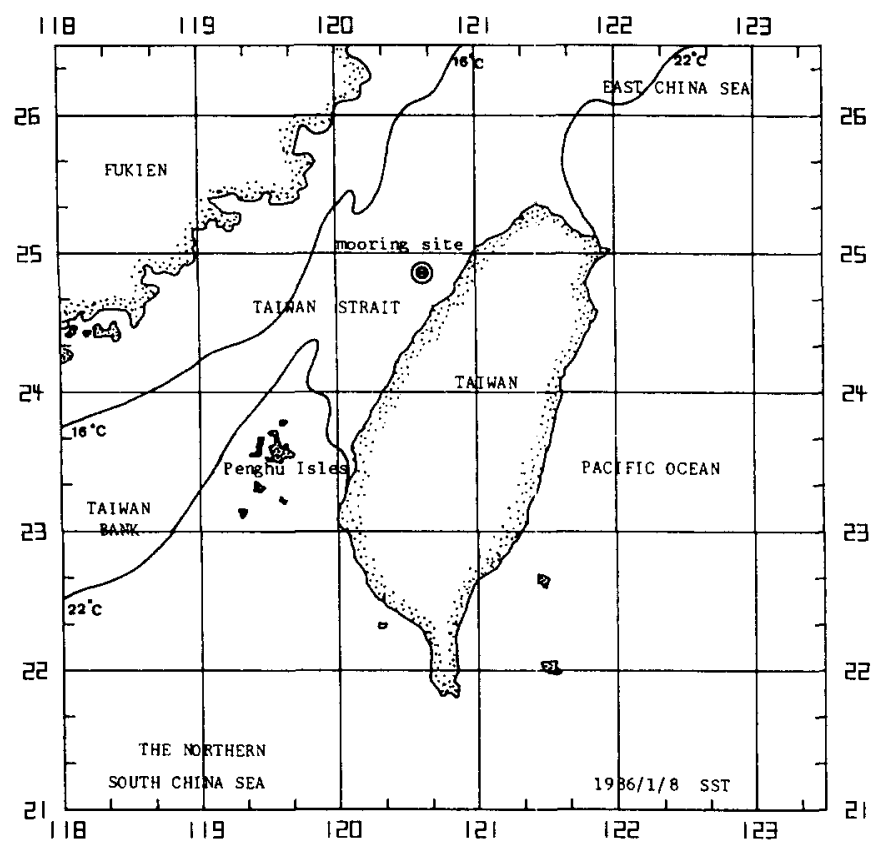

FIG. 1. The sea surface temperature (SST) distribution observed by TIROS-N/NOAA APT at January 8, 1986 (HuH, 1986). The location of instrument mooring is also shown.

addition, satellite IR images now available also reveal that a persistent thermal front meanders from the continental shelf of the East China Sea southwestward to the northern coast of Taiwan, and a separated one extends from the central coast of Taiwan westward then southwestward through the Taiwan Bank to the shelf off-shore Canton, during winter (HuH, 1986). Between the interrupted frontal zones is a bulge of cold water located in the central northern Taiwan Strait. A typical contour of SST illustrating these features is shown in Fig. 1. Since most of the major frontal systems in the world are continuous along continents between the shelf water and slope water, the frontal system near Taiwan is therefore unique, not only because of it being interrupted by an island, but also on account of the bulge of cold waters being trapped in the south of the northern entrance of the Taiwan Strait. According to CHU (1963), the surface water from the Kuroshio region can be differentiated easily from either the colder, fresher China coastal water or the warmer, but fresher, SCS surface water, by its warmer and more saline property. The existence of a thermal front in the central strait, i.e. the south edge of the cold water bulge, implies two things; one is the northward movement of the Kuroshio water having been stagnated by the front, so that there is no Kuroshio branch in the eastern strait when the frontal system stays there; the other is that cold waters in the central to the northern strait possibly form an independent gyre system during this period. Therefore, these observations are not completely consistent with the previous concept of a steady Kuroshio branch in the Taiwan Strait during winter.

The present article reports some preliminary results from field measurements in the Taiwan Strait, and is expected to clarify some aspects of the Kuroshio branch there. Since water flow within a shallow strait is greatly influenced by the winds above, the current we measured unavoidably fluctuates when the strong NE monsoon varies with the frequent 
passages of weather systems. Furthermore, the existence of a frontal structure in the strait also implies baroclinic variabilities, and provides further complexity for the flow fields. The branching process of the Kuroshio water in the strait is therefore complicated. From field measurements, however, the inception of it had been observed as a transient and intermittent event, which we would like to explain from the viewpoint of an intrusion process. Further, we shall show that the immature warm current develops gradually into a mature offshoot of Kuroshio water in late spring. These features will be reported later.

\section{HYDROGRAPHY OF THE TAIWAN STRAIT DURING WINTERTIME}

In order to understand the variation of density distribution in the Taiwan Strait, extensive hydrographic surveys had been performed routinely over past years. However, for a variety of reasons, the area studied had been restricted within the eastern half of the strait, and several cruises had been cancelled due to severe weather conditions. Typical results from a sequence of these surveys, from November 1985 through April 1986, are shown in Figs 2-5, where surface isotherms, isohalines and isopycnals for each cruise are adopted for illustrating the evolution of the hydrography of the strait over a typical winter. These figures show the frontogenesis and the frontolysis in the central strait, at which the bulge of cold water meets the southerly warm water and develops a persistent front from autumn to winter (Figs 2-4). However, the almost east-west aligned frontal zone in winter has evolved into one in spring whose alignment becomes roughly parallel to the axis of the strait, i.e. the northeast-southwest direction (Fig. 5). A tongue of warm water,

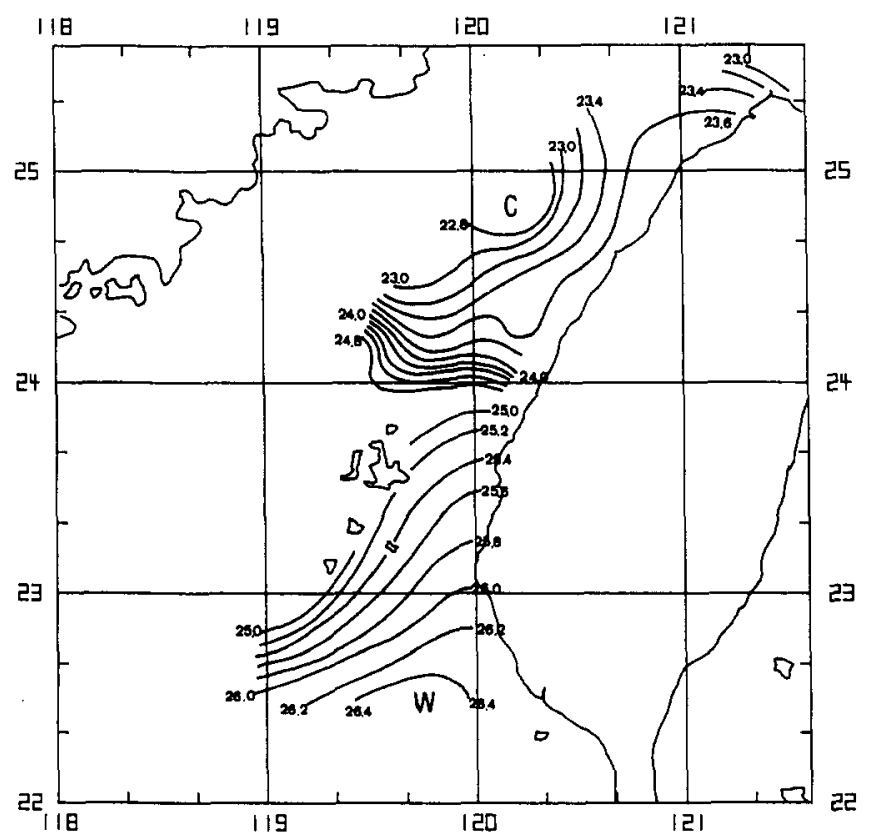

FIG. 2(a) 


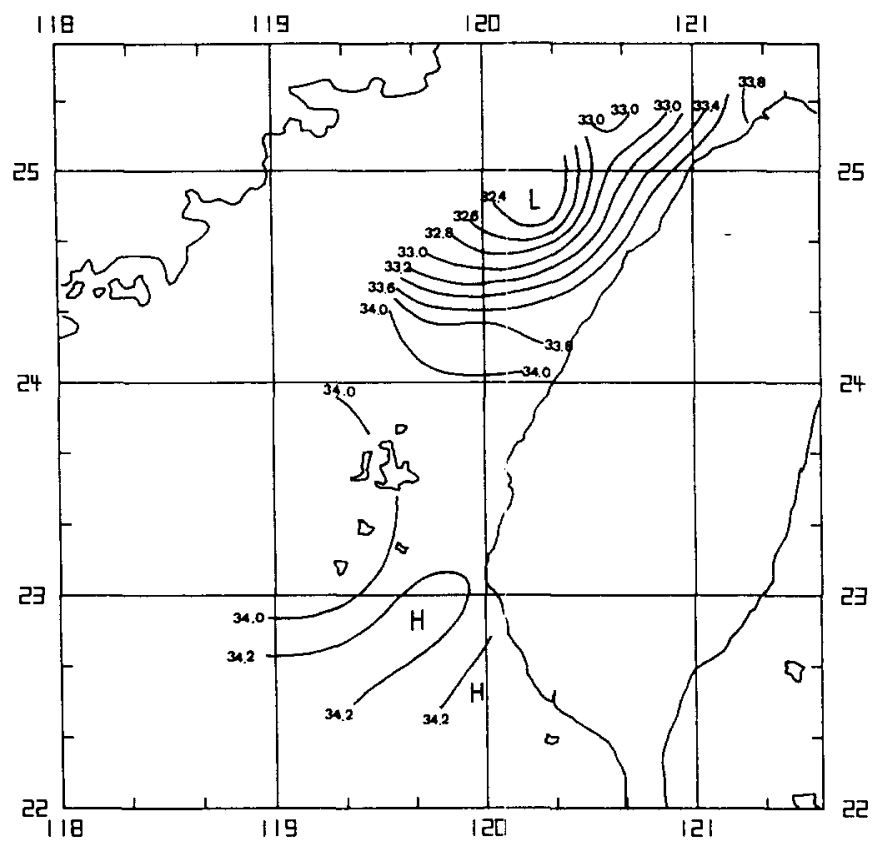

FIG. 2(b)

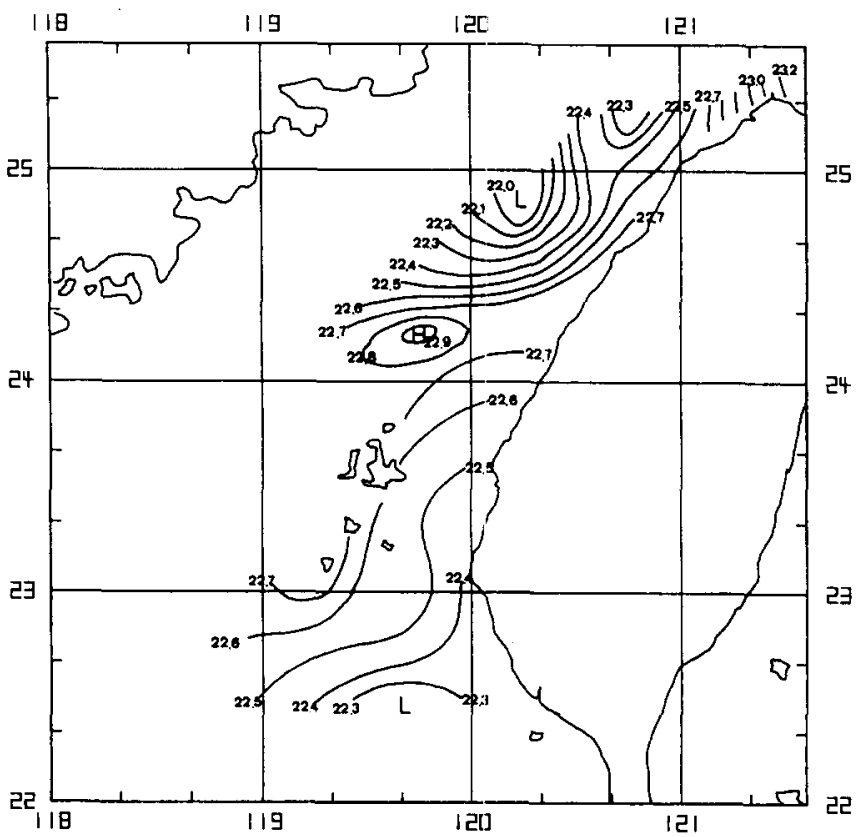

FIG. 2(c)

FiG. 2. Distribution of (a) isotherms $\left({ }^{\circ} \mathrm{C}\right)$, (b) isohalines $(\%)$ and $(\mathrm{c})$ isopycnals $\left(\sigma_{t}\right)$ at the surface during November 10-13, 1985. 


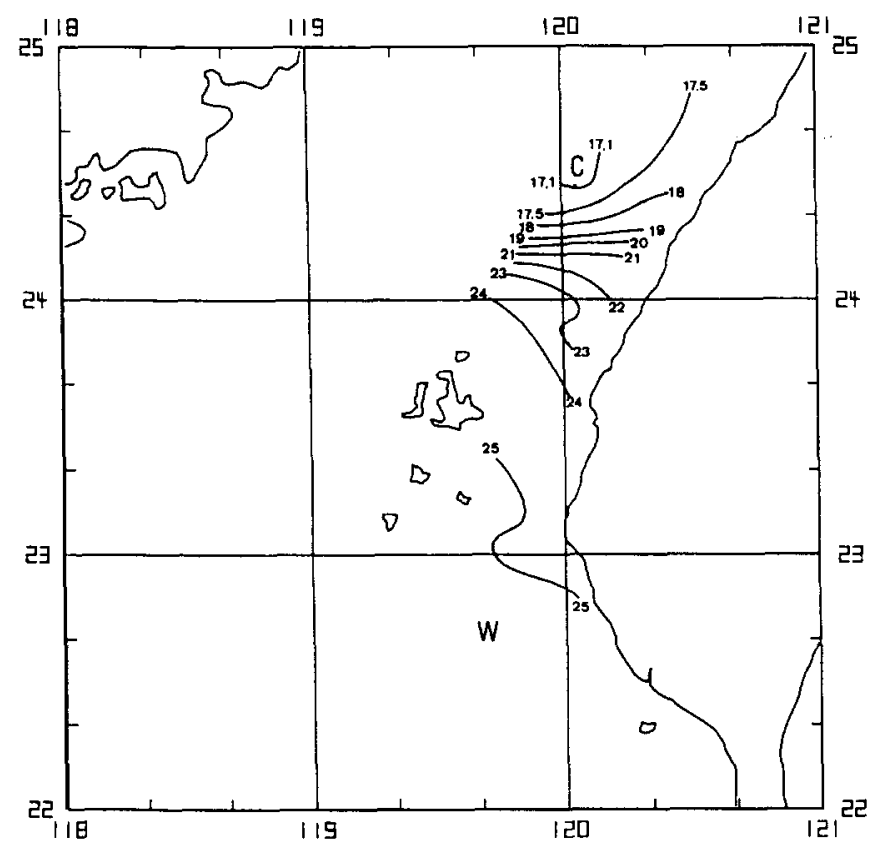

FIG. 3(a)

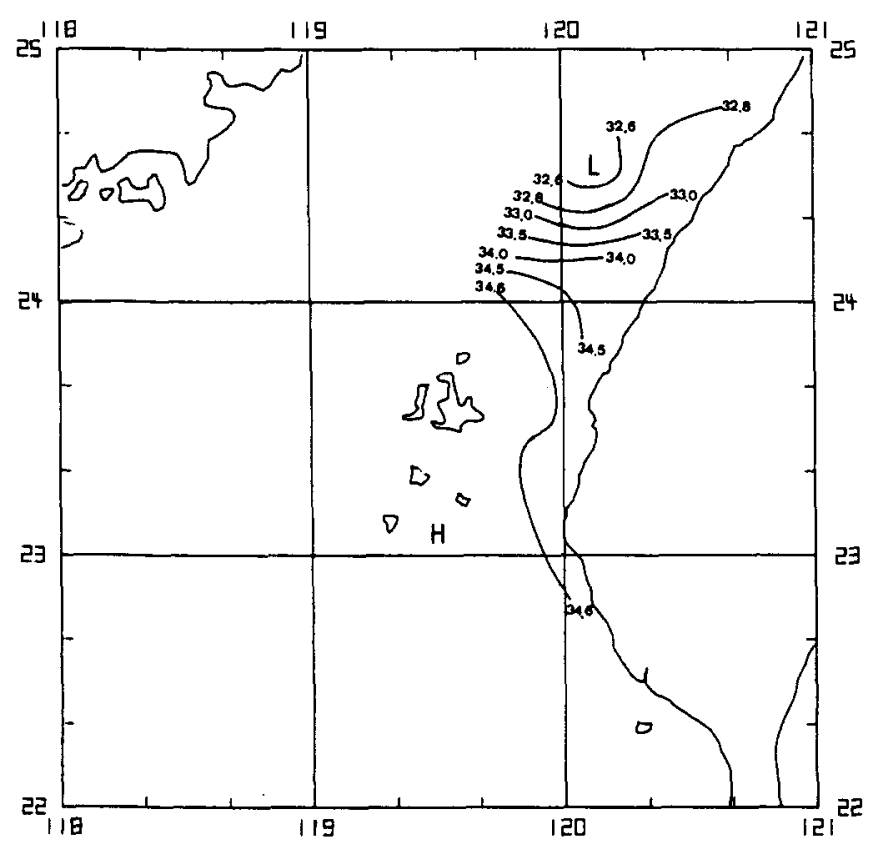

Fig. 3(b) 


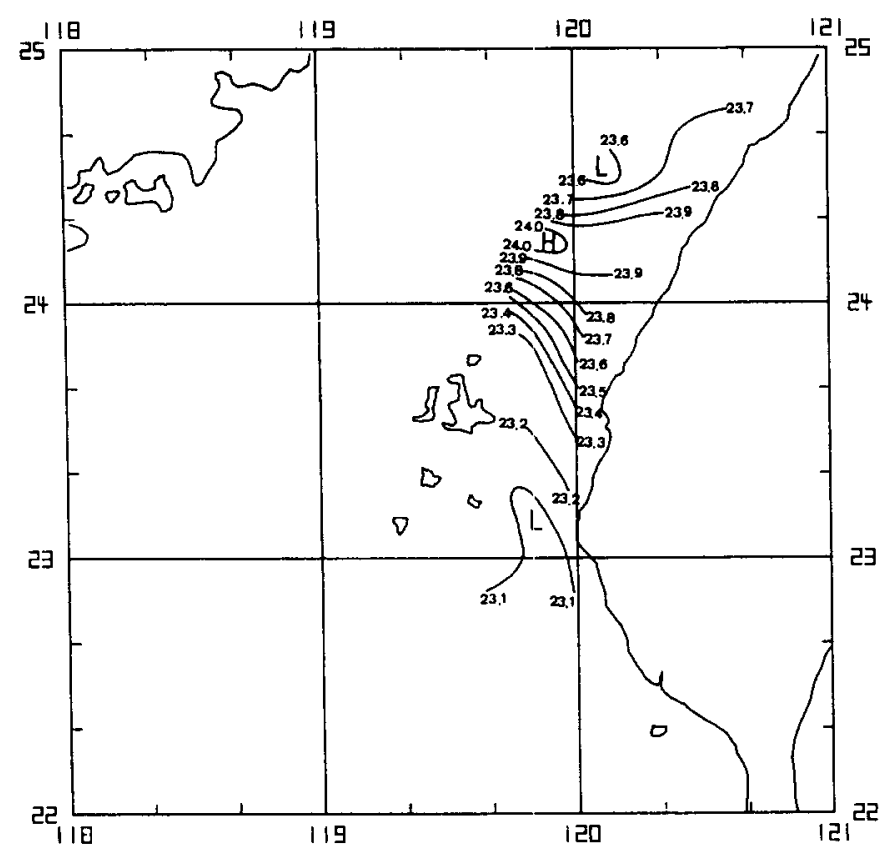

FiG. 3(c)

FIG. 3. Distribution of (a) isotherms $\left({ }^{\circ} \mathrm{C}\right),(\mathrm{b})$ isohalines $(\%)$, and $(\mathrm{c})$ isopycnals $\left(\sigma_{\mathrm{t}}\right)$ at the surface during December 27-29, 1985.

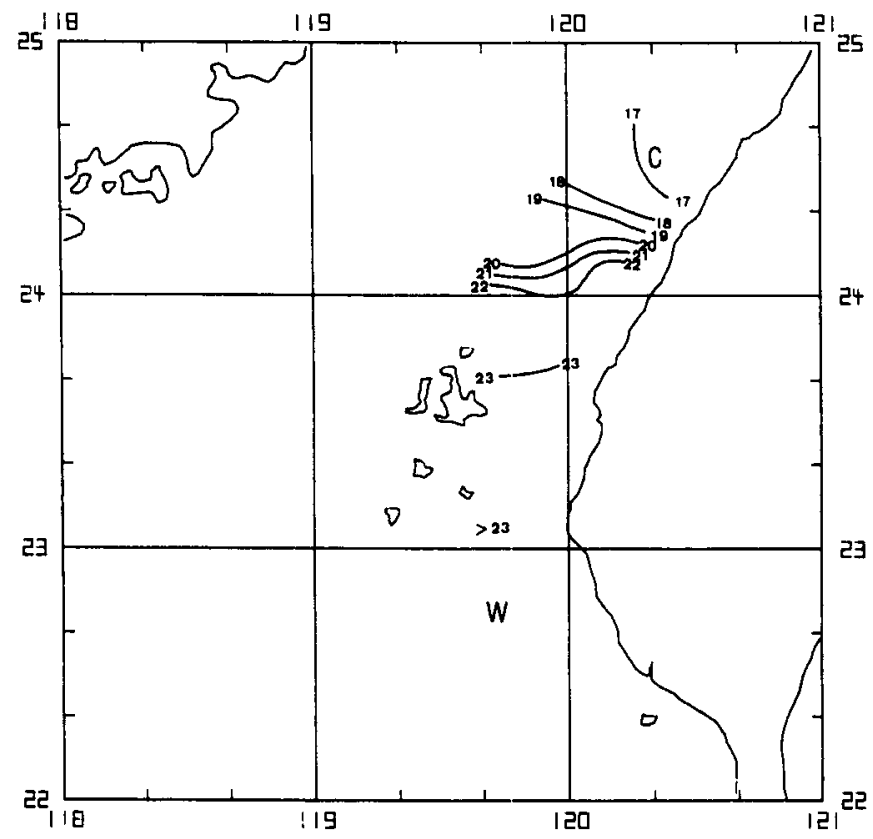

FIG. 4(a) 


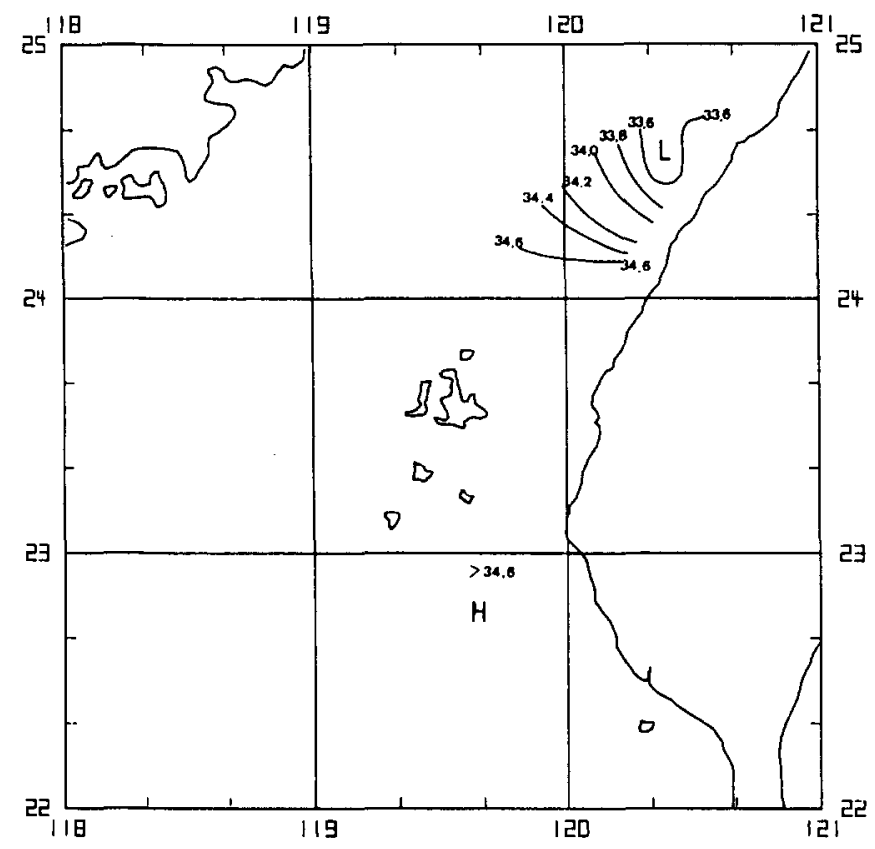

FiG. 4(b)

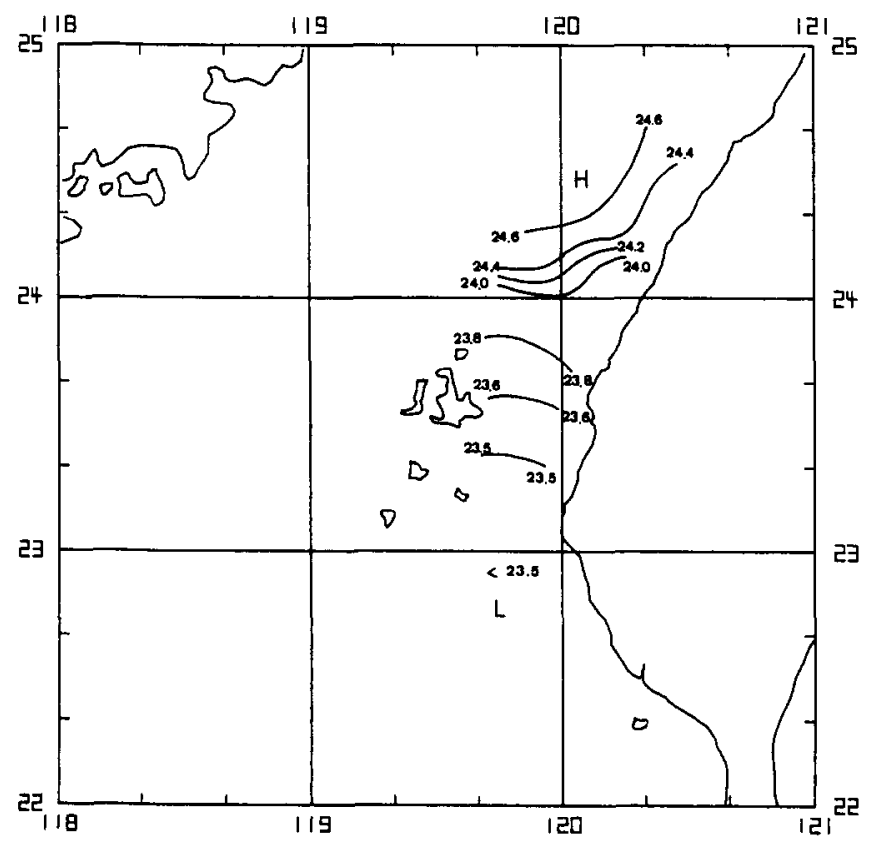

FiG. 4(c)

FIG. 4. Distribution of (a) isotherms $\left({ }^{\circ} \mathrm{C}\right)$, (b) isohalines $(\%)$, and (c) isopycnals $\left(\sigma_{t}\right)$ at the surface during January 10-12, 1986. 


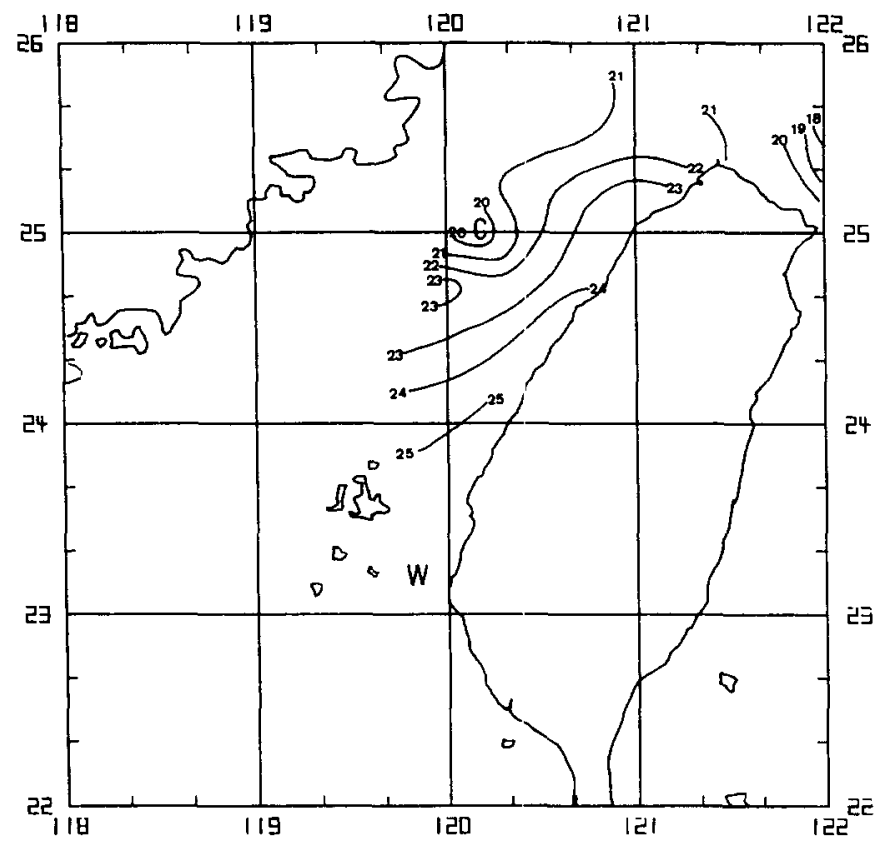

Fig. 5(a)

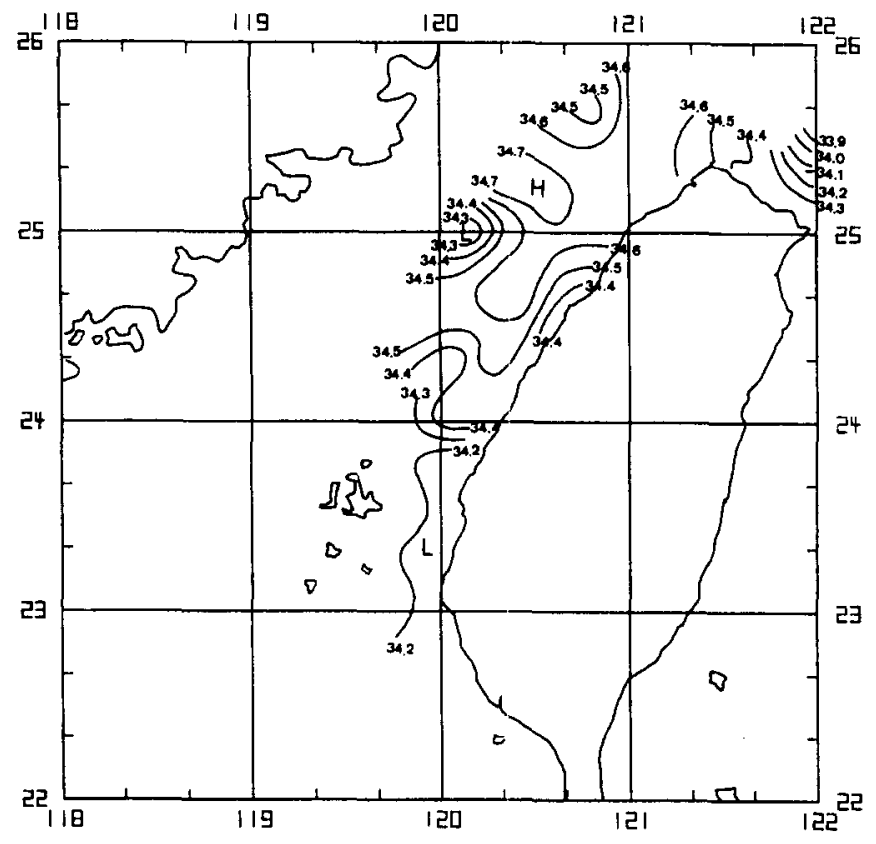

FIG. 5(b) 


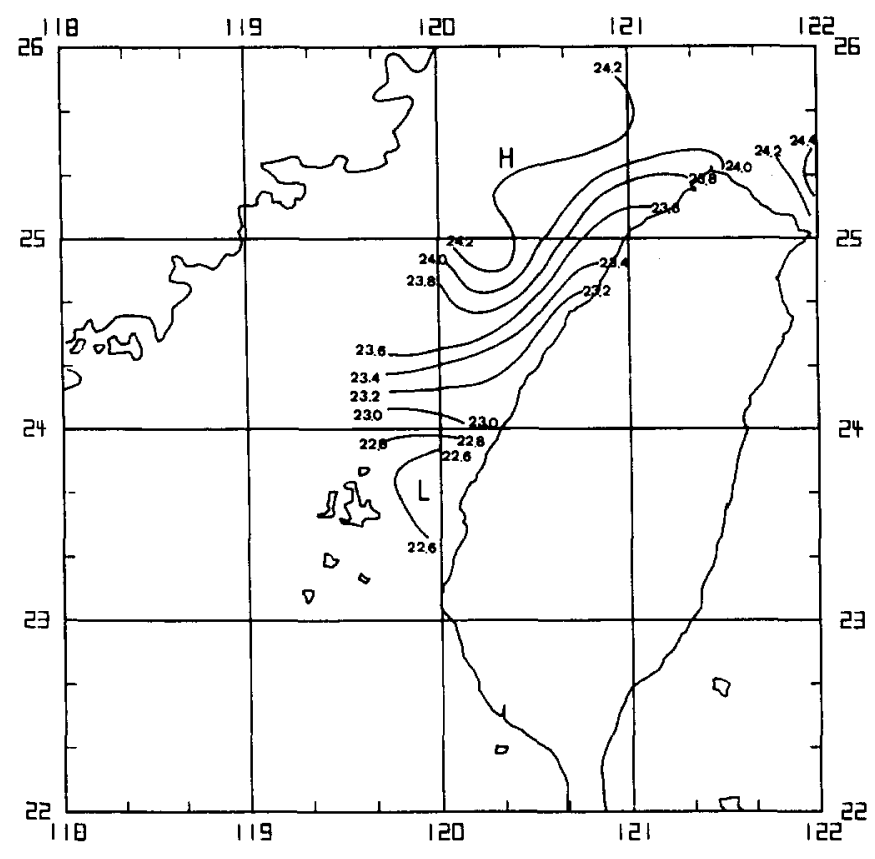

FIG. 5(c)

FIG. 5. Distribution of (a) isotherms $\left({ }^{\circ} \mathrm{C}\right)$, (b) isohalines $(\%)$, and (c) isopycnals $\left(\sigma_{\mathrm{t}}\right)$ at the surface during April 6-10, 1986.

extending upward from the south along the west coast of Taiwan, is also shown in Fig. 5. These patterns are important to the behavior of currents in the strait, and will be discussed later.

The sources of waters constituting the frontal system can be identified through the $T-S$ diagram (Fig. 6). In general, the transition of $T-S$ clusters encompassed by solid lines in Fig. 6 is more interesting, because it represents the evolution of physical properties for cold waters north of the front; we will pay more attention to this next. Because most of these $T-S$ data have been collected near the central portion of the strait, they will be hereinafter referenced as the central strait waters (CSW). On the other hand, the remaining clusters, which distribute vertically and are encompassed by a dashed line in Fig. 6, based on data gathered mainly at the southern strait, will be called the southern strait waters (SSW) for later reference.

From the $T-S$ diagram (Fig. 6), it is evident that the CSW is colder and fresher than the surface SSW. CHU $(1963,1971)$ had summarized three major water systems controlling the hydrography of the Taiwan Strait, i.e. the China coastal current, the SCS monsoon drift, and the Kuroshio branch. Perhaps it is not trivial to an average reader. It may be mentioned that the CSW originates mainly from the China coastal current because of its low temperature and salinity and that the SSW is from the Kuroshio region because of its relatively high temperature and salinity. However, three important features of the CSW shown in Fig. 6 have been noticed.

The first is the proportionate relation between water temperature and salinity of the CSW (Fig. 6), from which it is evident that the CSW is a mixture of the northerly China 


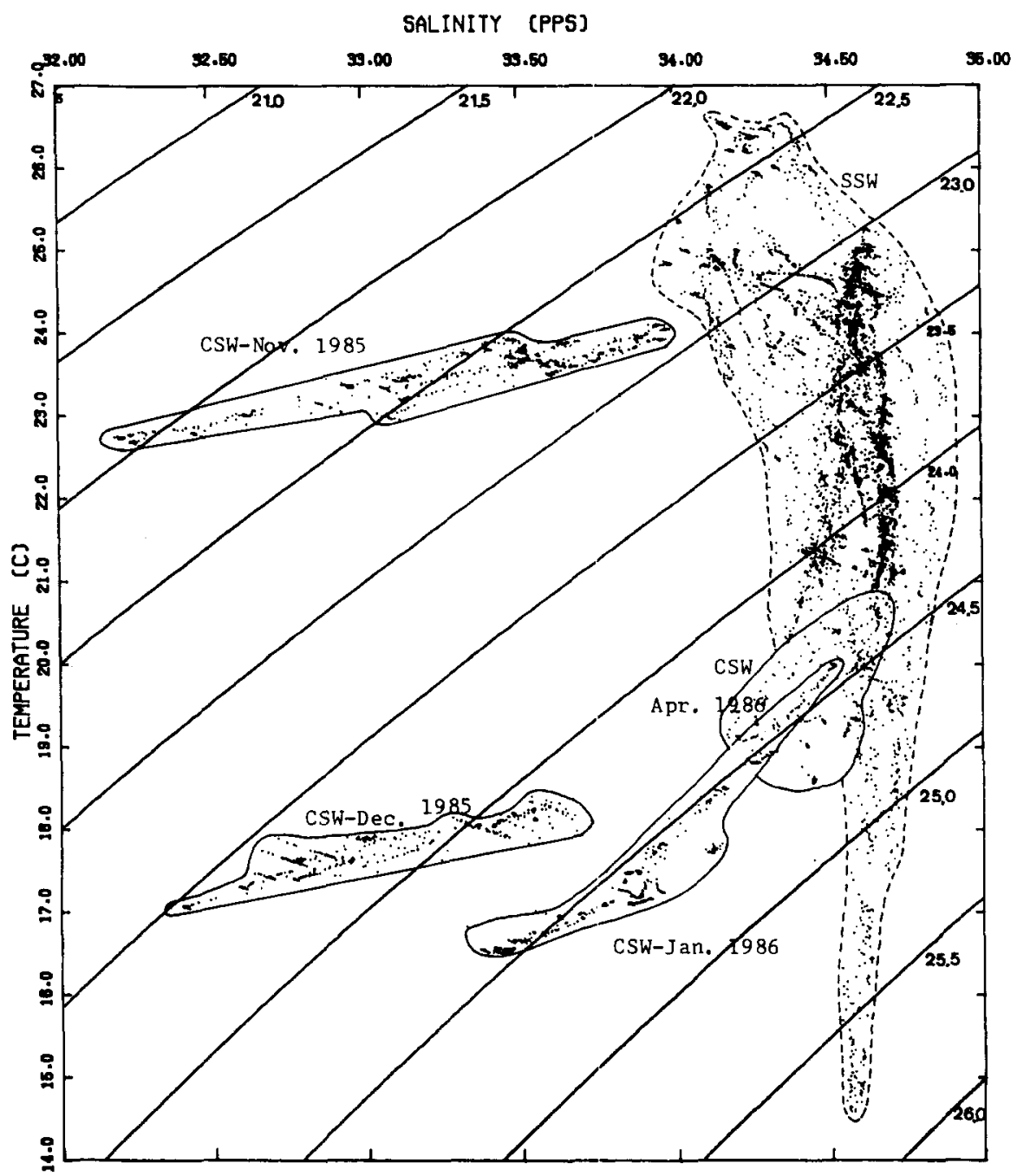

FIG. 6. The $T-S$ diagram for hydrographic data of the Taiwan Strait from November 1985 to April 1986.

coastal water (low $T$ and $S$ ) and the southerly Kuroshio water (high $T$ and $S$ ), because it distributes in the proportionate segment connecting the low $T, S$ and the high $T, S$ pairs. This will be discussed in detail next. In addition, it is obvious from Fig. 6 that water temperature is also a plausible index, at least for measurements by moored instruments in the strait, for discriminating the sources of incoming currents. This property will be referenced later for identifying the origin of the northeastward flows in the wintertime strait.

The second is the continuous cooling of the CSW from late autumn to winter, i.e. from November 1985 to January 1986 (Fig. 6). Obviously, this cooling process must rely either on the seasonal chilling effect or on the influx of recruiting cold waters from the west, i.e. the Fukien coastal region. Simultaneously with the cooling process, salinity of the CSW also increased (Fig. 6). Obviously, salinity is more conservative than temperature in the 
strait during wintertime. Therefore, the increment of salt content in the central strait implies one-way salt flux from the SSW to the CSW. Owing to the existence of the almost east-west aligned front from autumn through winter (Figs 2-4 and 6), direct exchange of water masses across the frontal zone may be assumed to be negligible, so that plausible processes for the remaining salt flux are possibly either horizontal mixing or advection by secondary flows during this period. On the other hand, salinity in the strait has increased remarkably from winter through spring (Figs 4-6). This may imply that the previously ignored primary process, such as the horizontal advection, now becomes possibly important and dominant to the process of salt transport in the strait. Anyway, from Fig. 6, it is obvious that remarkable amounts of the SSW had been entrained continually into the central strait since autumn. Furthermore, the $T-S$ appearance of the CSW in autumn and winter is also approximately associated with the geographic location, i.e. the colder and fresher the surface water is, the farther away from the frontal zone the observation is (in the cold region, of course). This property together with the process of salinity increments of the CSW motivate the above hypothesis on the salt flux in the strait.

The third is the spatial distribution and evolution of density field in the strait. The CSW is lighter than the SSW from late autumn through early winter (stage 1) (Figs 2, 3 and 6), and becomes partially heavier than the surface SSW from winter through spring (stage 2) (Figs 4-6). For dynamical reasons, the conditions of a horizontally non-uniform density distribution favor the intrusion of surface light fluids into the region which was originally occupied by heavy fluids (STERN, 1980; KUBOKAWA and HANAWA, 1984). We can expect two kinds of surface intrusion process from a variety of density distributions in the strait. During stage 1 , the density field favors northerly lighter cold-waters intruding into the eastern strait, and NE winds are constructive to this motion. During stage 2 , cold waters north of the front were further chilled, so that warm waters become relatively lighter, surface density distribution then reverses, and favors the intrusion of warm waters from the south. However, since NE winds are destructive to the intrusion of warm waters from the south, intrusive motions must await for the reduction of the strong monsoon wind, even though a favorable density distribution has already been established. In other words, the density distribution only provides one of the two sufficient conditions. The warm water intrusion event still has to be triggered by the collapse from the well-built forces balance, between wind stress, pressure gradient, inertial force, as well as Coriolis force, of the flow system. This situation usually appears when the most active driving force, the wind stress, relaxes suddenly. Therefore, exhibitions of the density field shown in Figs 2-6 provide indirect evidence and one of the sufficient conditions indicating the possibility of different intrusion processes in the Taiwan Strait.

The existence of an oceanic front in the Taiwan Strait is indeed important to the behavior of the Kuroshio branch. Previous observations report that the front is mainly a thermal and saline front in winter. The frontal system also separates the colder, fresher China coastal water to the north, from the warmer, more saline Kuroshio water to the south. These facts denote that the Kuroshio waters can not flow through the eastern strait directly without interrupting the almost east-west aligned frontal zone in the central strait. Since the location of the front is quite stationary in winter, it is confident that a through-channel Kuroshio branch is not existent in the Taiwan Strait during most of winter days, as the field observations emerge. 


\section{MEASUREMENTS FROM MOORED INSTRUMENTS IN THE TAIWAN STRAIT}

In addition to the extensive hydrographic surveys discussed previously, the Institute of Oceanography, National Taiwan University has also maintained since the summer of 1984 a long-term mooring station including three current meters (their nominal depths are $15 \mathrm{~m}$, $30 \mathrm{~m}$ and $50 \mathrm{~m}$, respectively), a thermistor string, and a tide gauge in the Taiwan Strait (Fig. 1). The water depth of the mooring site is about $65 \mathrm{~m}$. The oceanic wind field is also measured by an acoustic anemometer installed on a nearby oil rig (only hundreds of meters away from these moored equipments). Some of the basic statistics and general properties of the current field as well as wind field, and the characteristics of water temperature had been described in detail by WANG and ChERN (1985), WANG, CHERN, Wu and CherN (1986), and Wang, Chern, Chen and Huang (1987).

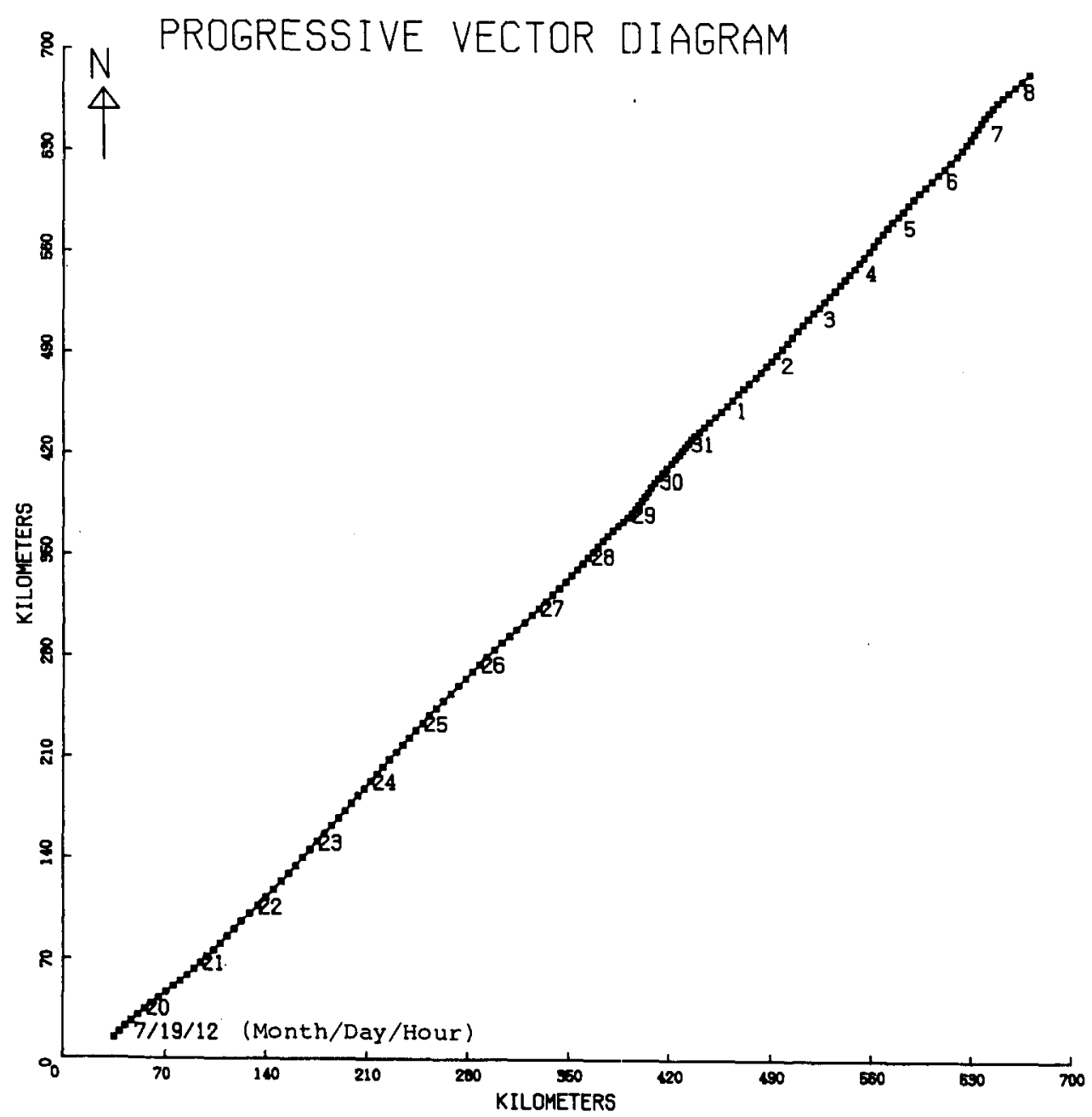

FIG. 7(a) 


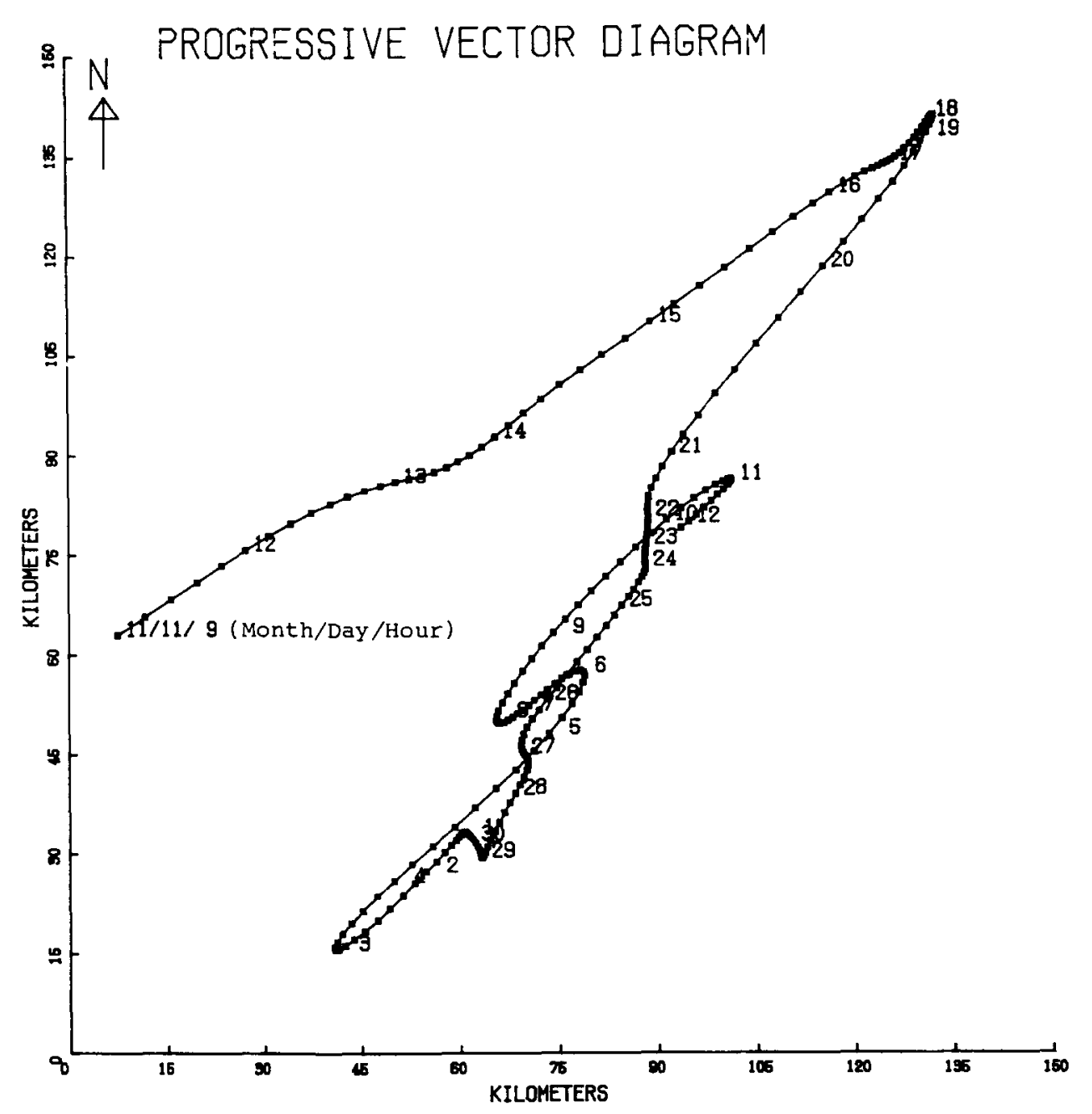

FiG. 7(b)

FIG. 7. The PVD of low-passed (the half power period is $40 \mathrm{~h}$ ) currents at the mooring site (Fig. 1). (a) A typical case in summer, from July 19 to August 8, 1984. The nominal depth is $15 \mathrm{~m}$. (b) A typical case in winter, from November 11 to December 12, 1984. The nominal depth is also $15 \mathrm{~m}$. Since the flow field at the mooring site is usually vertically uniform, only the top one is adopted for illustration here and in the following figures.

Generally speaking, observed oceanic currents are quite steady in the Taiwan Strait except during the NE monsoon season. Typical Progressive Vector Diagrams (PVD) of currents in summer and winter, shown in Fig. 7a, b, illustrate this feature qualitatively. In winter, the monthly averaged mean current is not stationary, and is rather sluggish $\left(2-15 \mathrm{~cm} \mathrm{~s}^{-1}\right)$ from December through February. On the contrary, the fluctuant current is relatively strong with the amplitude of the order of $20-40 \mathrm{~cm} \mathrm{~s}^{-1}$, and alternates closely with monsoon winds. Overall currents flow southwestward when the NE monsoon overwhelms, and reverse to the northeast when the wind is weak or disappears (WANG and CHERN, 1987). However, these northeastward water flows do not necessarily associate with 


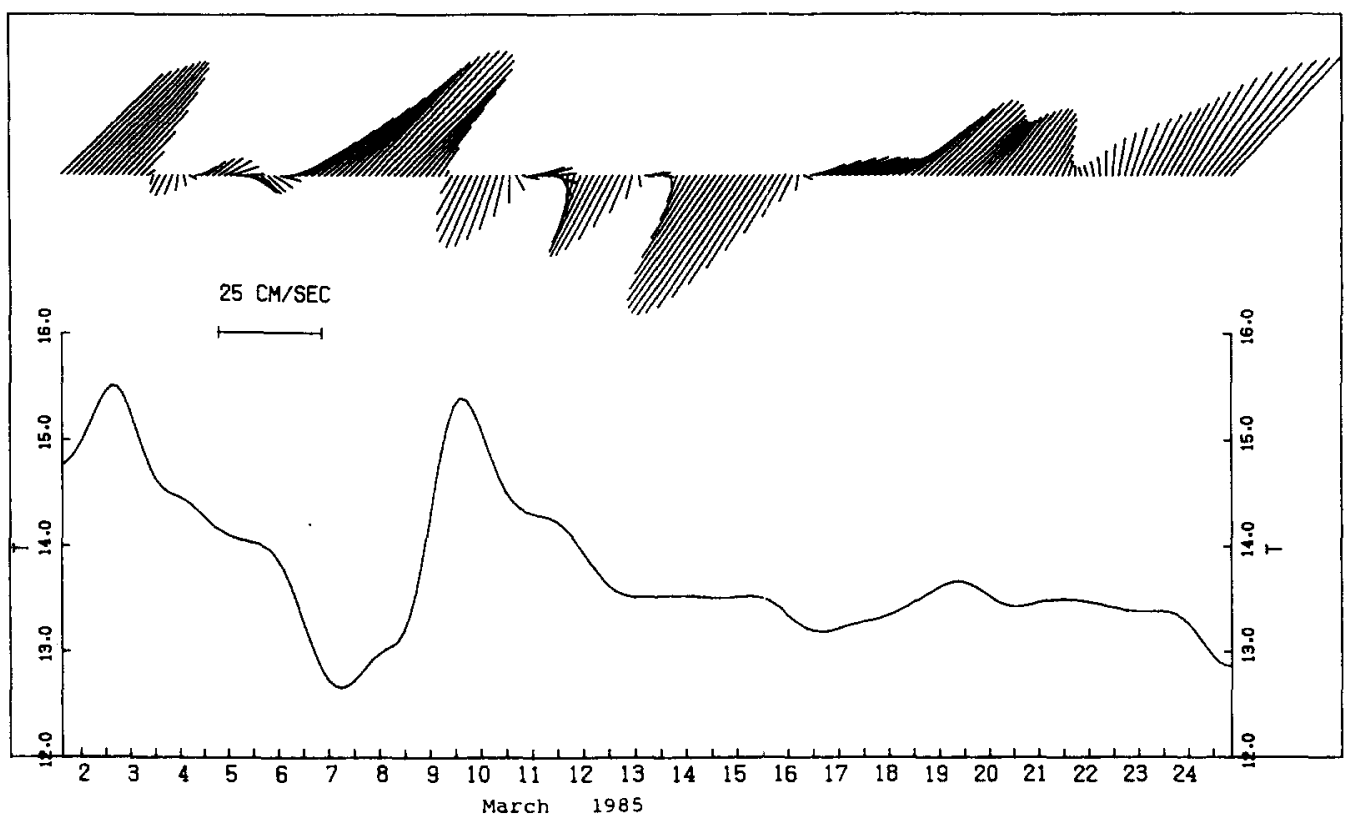

FiG. 8. A typical stick diagram of low-passed currents and the time history of low-passed water temperature $\left({ }^{\circ} \mathrm{C}\right)$ at the mooring site in winter, from March 1 to 24,1985 . The nominal depth of the instrument is $15 \mathrm{~m}$. The low temperature associated with the northeastward flows implies that the current is not an offshoot from the Kuroshio branch.

the Kuroshio branch in any event, because their temperature is too low to be identified as coming from the Kuroshio region. On the other hand, based on the $T-S$ relation discussed earlier, these waters can be traced as originating from the China coastal current. A typical example is shown in Fig. 8, where the stick diagram and time history of water temperature show that during March 1985 , the water is quite cold $\left(<16^{\circ} \mathrm{C}\right.$, typical surface temperature for the SSW in winter is always $>23^{\circ} \mathrm{C}$, for example), northeastward currents still dominate. Therefore,the long-term measurements provide direct evidence revealing that there are no steady Kuroshio waters flowing into the central or northern Taiwan Strait from autumn through winter, or at least to early winter.

However, Kuroshio waters do flow into the Taiwan Strait, but the process is rather various, the inception of it is often intermittent, and a steady offshoot of Kuroshio waters begins a little late. The inception of the Kuroshio branch observed in the strait starts usually from a warm water intrusion event. An example of this process appearing from January 19 through 22, 1986 (Figs 9 to 11) illustrates the phenomenon. Similar events had been also observed during February 8-15, 1985 (WANG and CHERN, 1985), and March $8-19,1987$ (unpublished result by the authors). The stick diagram of wind fields observed concurrently near the mooring site (Fig. 9) shows that the NE monsoon is predominant and fluctuant, with periods of 3-12 days, during these measurements. Comparisons of the along-shore component of both winds and currents show that they are closely correlated with winds leading currents by a few hours (Fig. 12). From previous discussions, we know that the density distribution before the intrusion event (Fig. 4) shows waters south of the front becoming lighter than those to the north, and we also know that there must be a southwestward piling-up of water surface due to the wind stress exerted by the gusty NE 


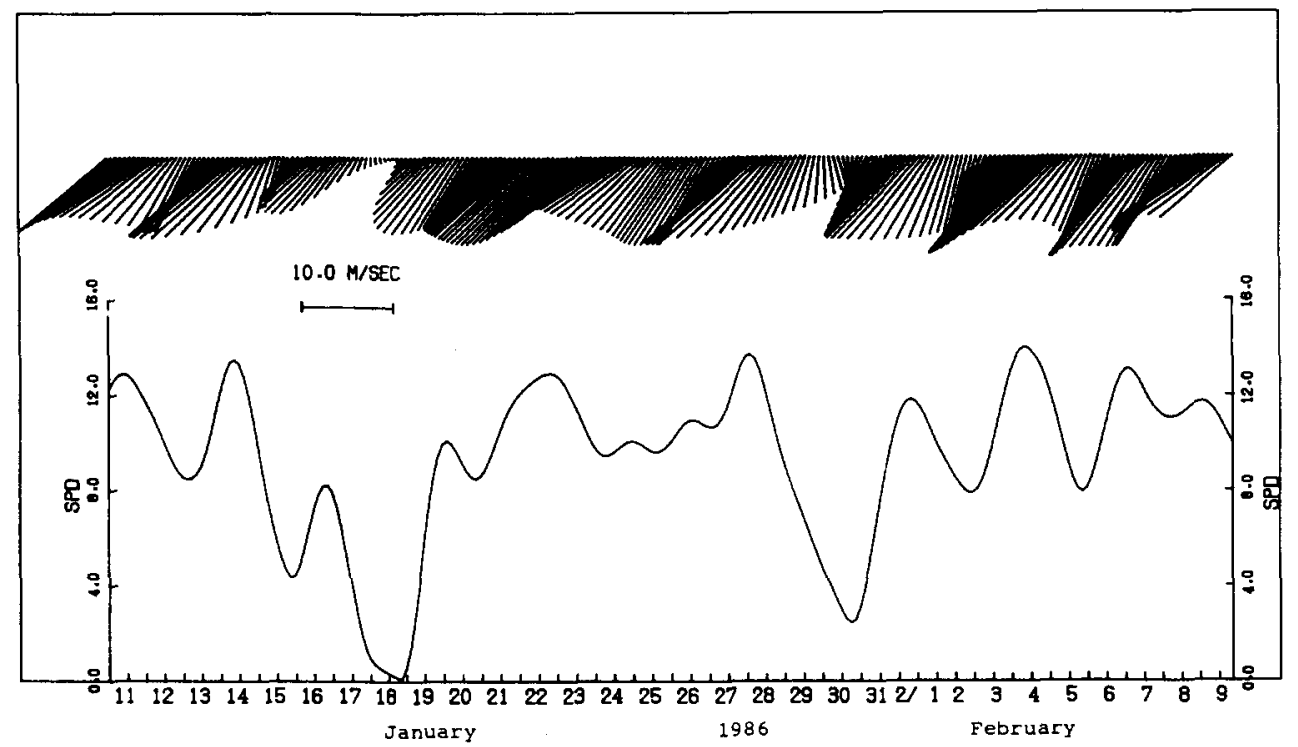

FIG. 9. Low-passed wind field measured near the mooring site, from January 10-February 8, 1986.

The bottom panel shows the variation of wind speed in $\mathrm{m} \mathrm{s}^{-1}$.

monsoon in the meanwhile (CSANADY, 1982). After the rapid wane of winds from January 17 through 19 (Fig. 9), the piled-up water level south of the front then provides initial impulsions for the northeastward intrusion of warm waters, because the wind stress is no longer in competition with the gradient of surface elevations now. Figure 10, the time history of isotherms at the mooring site, together with current vectors in Fig. 11, show the event of this warm current intrusion. The transition from a roughly well-mixed water column at the mooring site into a stratified one, and the wavy appearance of the bottom

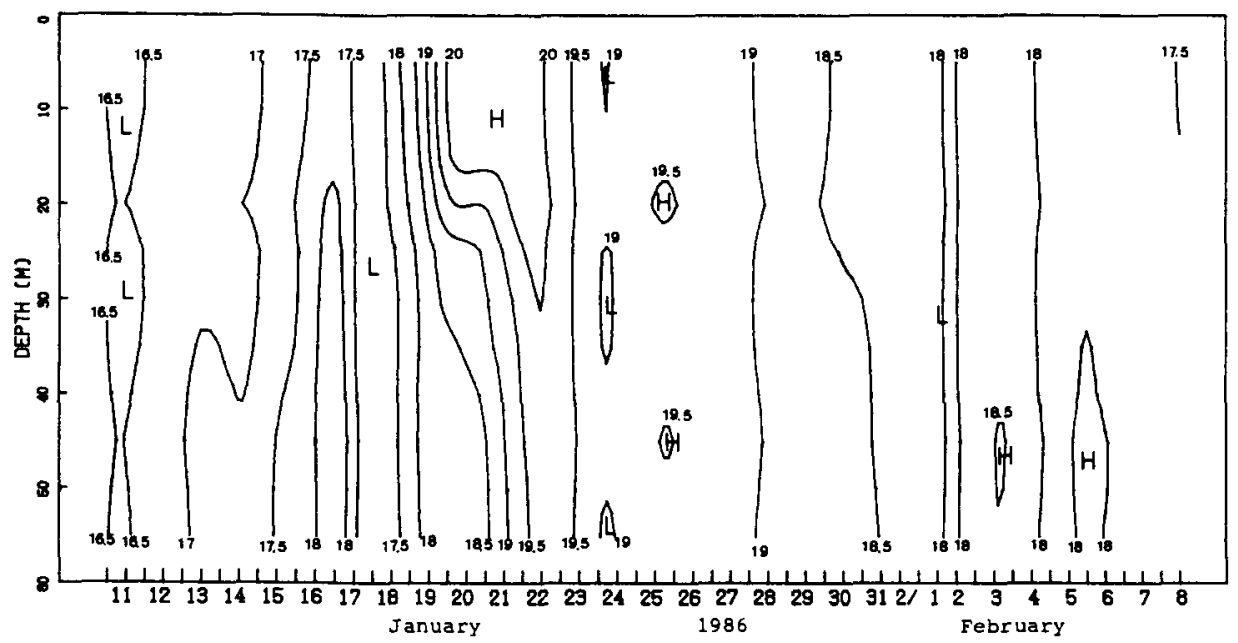

FIG. 10. Time history of the vertical profile of low-passed temperature $\left({ }^{\circ} \mathrm{C}\right)$ at the mooring site from January 10 to February 8,1986 . The instrument contains 11 thermistor chains spanning evenly over $50 \mathrm{~m}$. The nominal depth of the top one is $5 \mathrm{~m}$. 


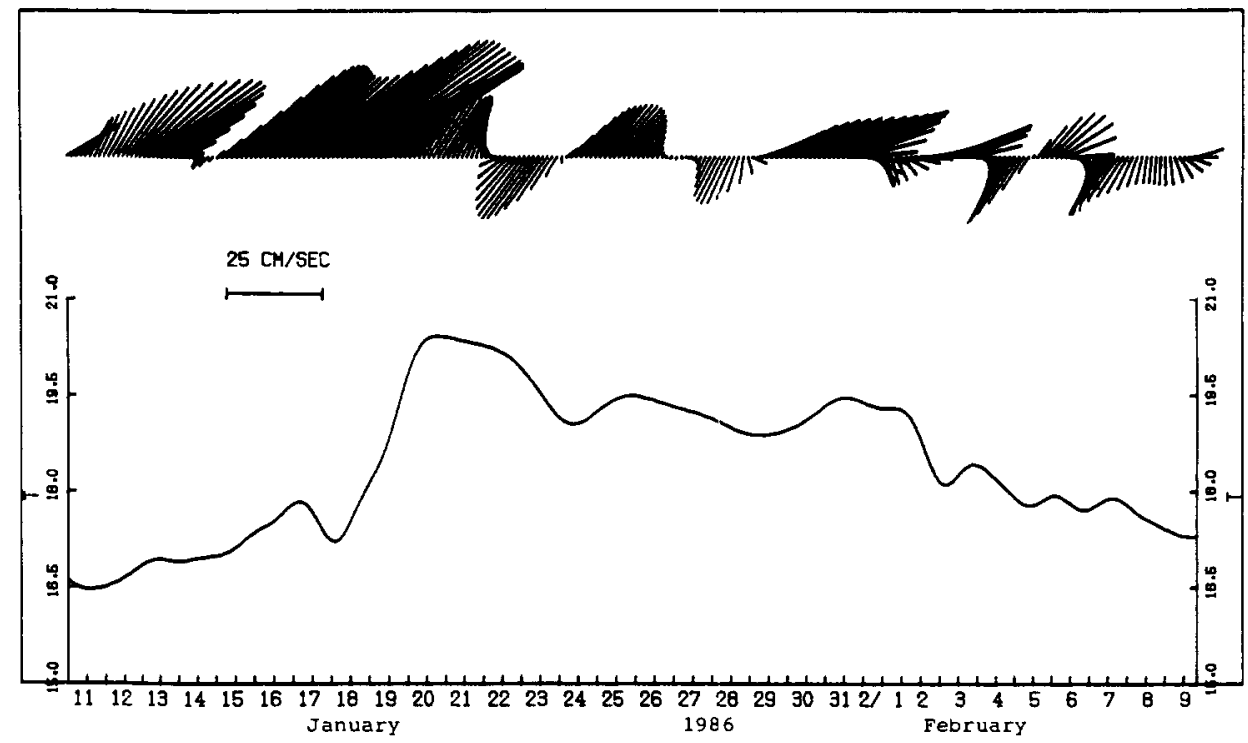

FIG. 11. Time history of low-passed currents and water temperature $\left({ }^{\circ} \mathrm{C}\right)$ at the mooring site from January 10 to February 8,1986 . The nominal depth of the instrument is $15 \mathrm{~m}$, and the water depth is $65 \mathrm{~m}$.

of the upper layer during intrusion, from January 19 through 22 (Fig. 10), as well as the strong northeastward current associated with an on-shore component (the azimuth angle of the local coastal line is about $45^{\circ} \mathrm{T}$ ), are good exhibitions of the behavior of intrusive motions.

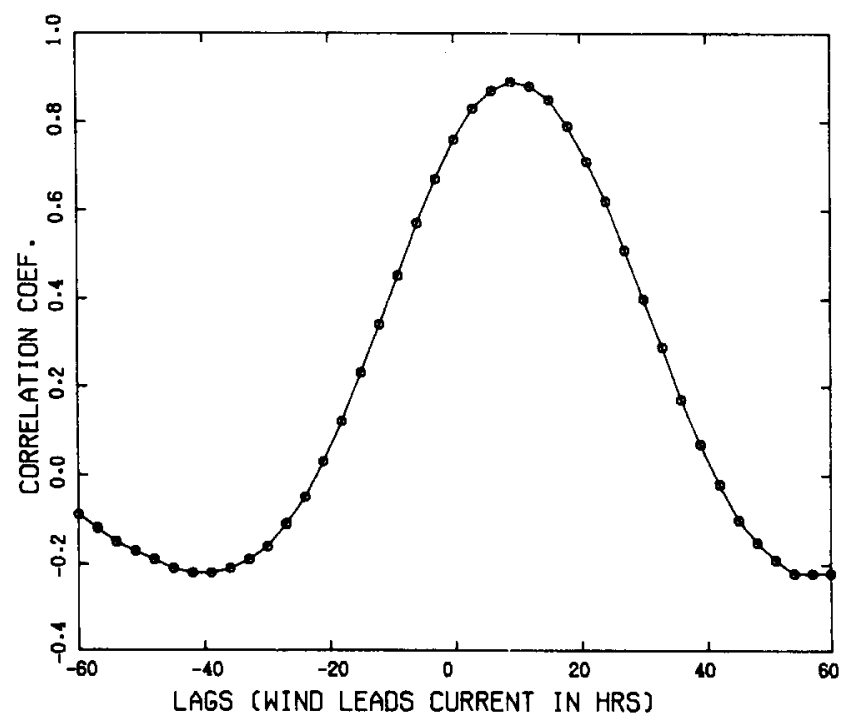

FiG. 12(a) 


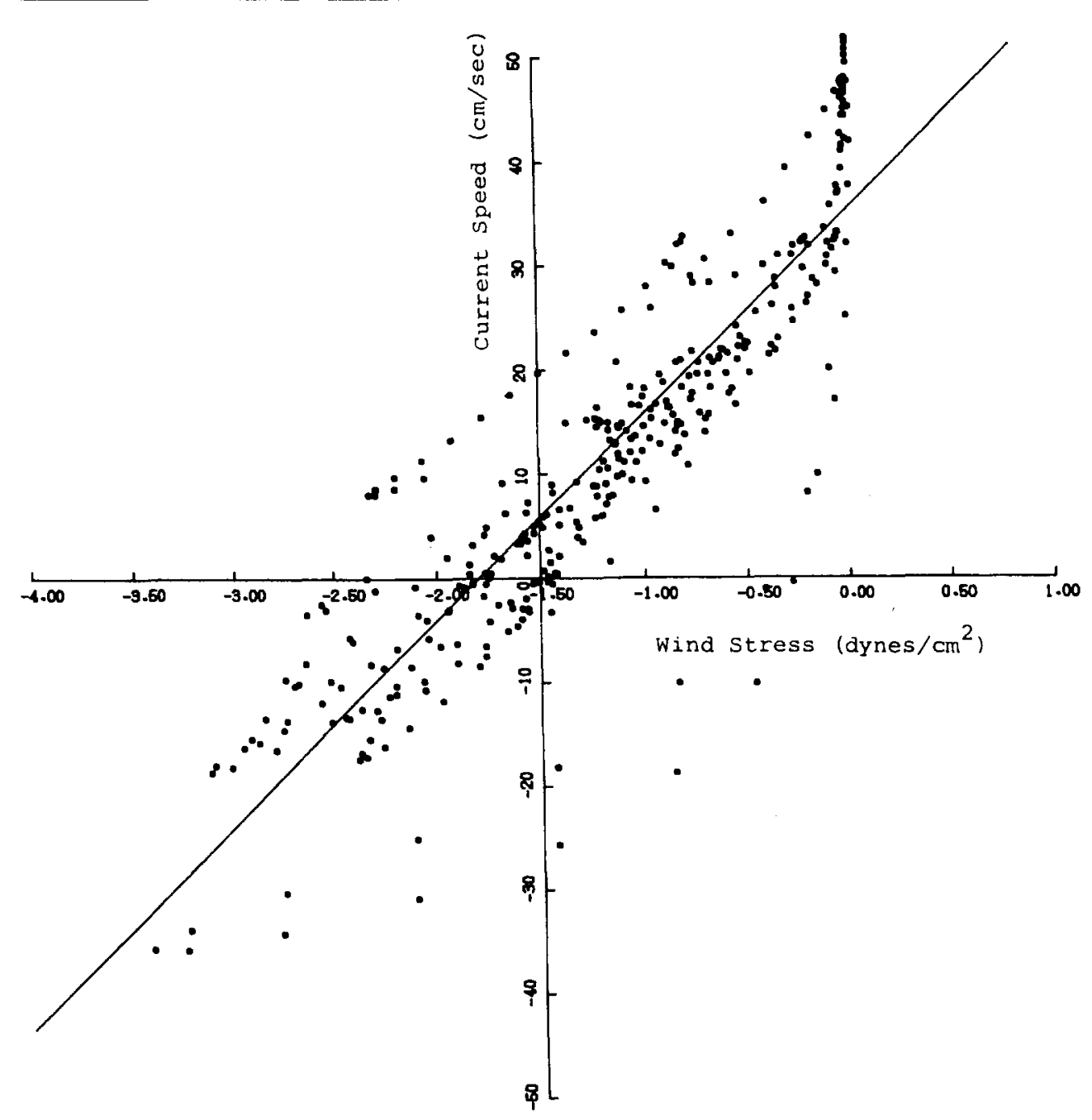

Fig. 12(b)

Fig. 12. (a) Correlation between the along-shore component of the low-passed wind stress and those of currents $(15 \mathrm{~m})$. The maximum correlation coefficient is 0.89 when the wind stress leads currents by $9 \mathrm{~h}$. (b) Scatter diagram of the along-shore component of the wind stress versus those of the $9 \mathrm{~h}$ lagged currents, where the negative value of either winds or currents associates with a southwestward flow, and the data used in both (a) and (b) are the same as those in

Figs 9 and 11 .

Two days after the inception of the warm water intrusion event on January 17, winds had enhanced again (Fig. 9), but northeastward currents were still active for two more days (Fig. 11). Temperature of intruded waters remained relatively high after the end of the intrusion event, even though the NE wind had blown for a while and the air was already well-chilled. Furthermore, this relatively warm sea situation had been maintained until the obvious and persistent temperature drop which started from 2 February. In the meanwhile, currents reversed alternately from northeast to southwest as NE winds fluctuated. Since the mean current was sluggish during that period, these observations implied that intruded warm waters (having strong currents during the inception stage) had 
lost their original forward momenta, and had been entrained within the central strait after the enhancement again of NE winds. This event provided a straight process for exchange for the water masses through the central strait, so that it was definitely important to the later increment of salt content there. When the first event of the warm water intrusion terminated, waters in the central strait had been chilled since February 2 (Figs 10 and 11). This further indicated the returning or rebuilding of the thermal front in the eastern strait, because during the previously warm water intrusion event, the originally east-west aligned frontal zone had retreated westward and left room along the eastern strait for the penetration of warm waters from the south. In the meanwhile, salinity of the CSW had been increased remarkably due to entrainments of intruded waters (Figs 5 and 6). The increment of salt would further enhance the horizontal density contrast across the rebuilt frontal zone, and provided favorable conditions for the next warm water intrusion event appearing as soon as the strong NE winds wane again.

From the above-mentioned current meter measurements and hydrographic observations in the Taiwan Strait, we know that the warm water intrusion process provides a direct exchange of water masses in the strait. This process is more efficient than the horizontal diffusion, and is therefore important to the later evolution of the density structure in the strait. During such an intrusion event, the frontal system would retreat westward and tilt anti-clockwise for a while to leave room for the penetration of warm waters from the south along the eastern strait. Salinity in the eastern strait then increased due to the addition of these intrusive saline waters. However, when the NE wind blew again, especially after the intensification of the continental high pressure system in the Chinese mainland or the passage of a strong atmospheric cold front, the frontal system in the strait was either rebuilt or turned back, but density contrast across the frontal zone was enhanced due to the mixing of the CSW with the entrained saline waters, as well as the recruiting cold waters from the China coastal current in the eastern strait. This favored the later warm water intrusion event appearing possibly during the ensuing reduction of the strong NE wind. After several such intrusion events, the density distribution becomes more favorable for the intrusive warm current than before. In the meanwhile, the gusty NE winds also gradually exhaust. This is the typical behavior for the seasonal transition of monsoon from winter to spring. Sooner or later a quasi-steady, through-strait warm current along the west coast of Taiwan was then established. This quasi-steady offshoot of the Kuroshio branch had been observed mainly from spring through early summer (WANG, CHERN, CHEN and HuANG, 1987). Figures 13 and 14, being typical examples, illustrate the behavior of how the Kuroshio branch evolves from such an immature flow to a quasi-steady current in the strait.

\section{DISCUSSION AND CONCLUDING REMARKS}

Past investigations reported that warm and saline waters originating from the Kuroshio region occupied the NSCS during wintertime. These waters were called the Kuroshio branch, and it had long been believed that a steady offshoot of them would flow continuously along the west coast of Taiwan in winter (CHU, 1963; FAN, 1982). However, this feature is not completely consistent with recent evidence.

Field measurements now available display that the wintertime hydrography, in both the Taiwan Strait and the NSCS, are influenced mainly by multiple intrusion events, from the China coastal water and the Kuroshio surface water, and from seasonal chilling effects. 


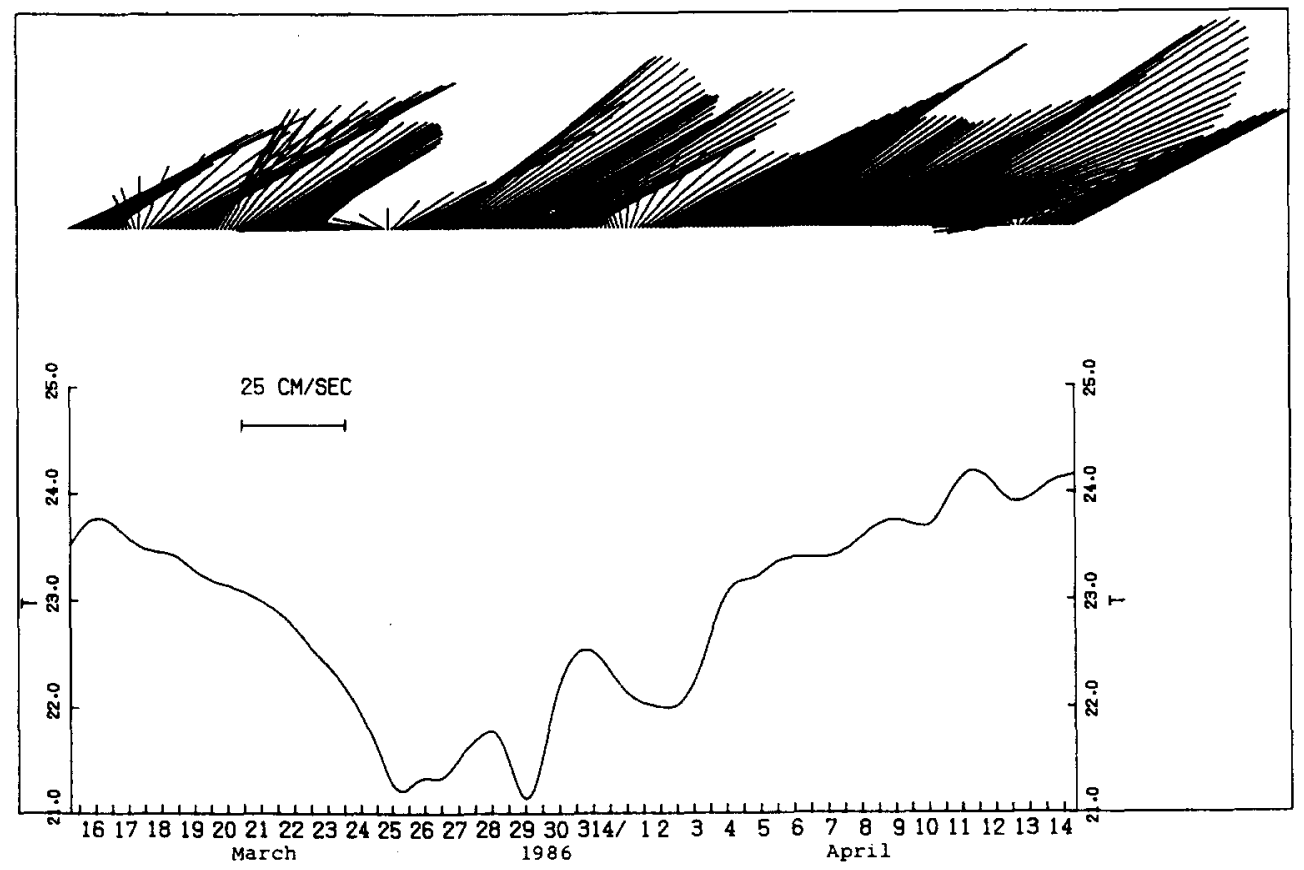

Fig. 13. A typical record of low-passed currents and temperature $\left({ }^{\circ} \mathrm{C}\right)$ at the mooring site, from March 15 to April 14, 1986, showing the fluctuant feature of the intrusive warm current. The nominal depth of the instrument is $15 \mathrm{~m}$.

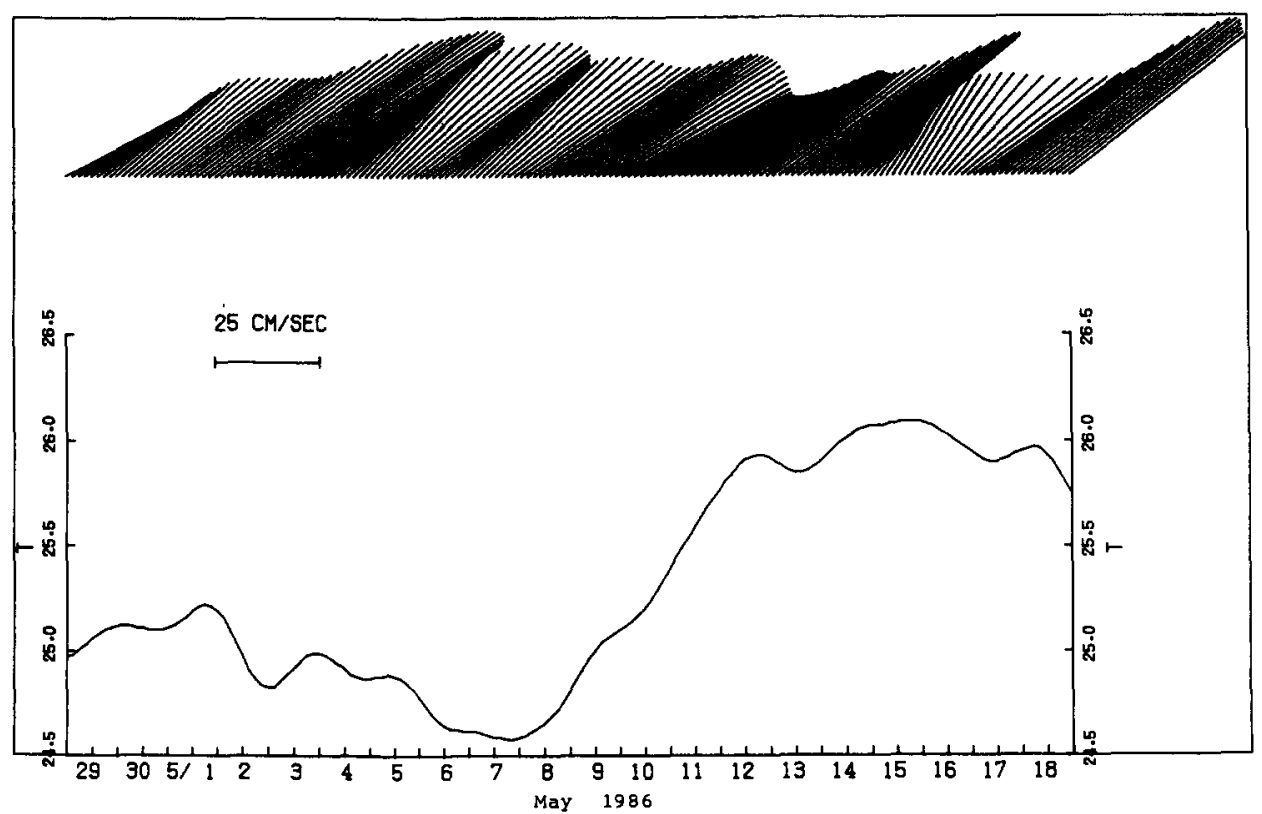

Fig. 14. A typical record of low-passed currents and temperature $\left({ }^{\circ} \mathrm{C}\right)$ at the mooring site, from April 28 to May 18, 1986, illustrating the quasi-steady flows of the Kuroshio branch. The nominal depth of the instrument is $15 \mathrm{~m}$. 
These intrusion processes depend strongly on both the strength of monsoon winds and density distributions in the strait. Since the density structure of water in a shallow sea is also greatly influenced by the air flowing over the surface, the behavior of intrusion events therefore also depends indirectly on the spatially uneven heat flux through the sea surface. Roughly speaking, the coolness of the passing weather systems is also an important factor, among the others, for regulating the intrusive motion and inducing the variation of hydrography in both the strait and the NSCS, because the recruiting cold waters from the shallow China coastal region have been influenced by these weather systems.

Along with the hydrographic surveys, long-term moored observations of currents had been made in the eastern Taiwan Strait. These data reveal that the monthly averaged mean current is sluggish in winter and that the mean speed is only $2-15 \mathrm{~cm} \mathrm{~s}^{-1}$ from December through February (the typical value for a summer month is about $35-50 \mathrm{~cm} \mathrm{~s}^{-1}$, for comparison) and the direction of the mean flow varies in different months. On the other hand, the fluctuant current is relatively strong and alternates closely with the variation of the strength of monsoon winds. Its amplitude is of the order of $20-40 \mathrm{~cm} \mathrm{~s}^{-1}$, and the direction of pulsating currents is steady and roughly parallel with the transverse of the strait. Temperature records from the moored equipment provide important clues for tracing the origin of incoming waters. Although the northeastward flows dominate over the wintertime measurements, these currents do not necessarily associate with the Kuroshio branch. Two kinds of situation had been observed from these winter data. One is the northeastward flow accompanied with cold waters, and the other shows a similar flow but a rapid rise in water temperature had emerged. The former is usual in winter, but the latter is intermittent and only appears after several particular conditions are provided. Combining the characteristics drawn from the current measurements and those revealed from hydrographic data as well as the observations of the winds, a general picture of the flow pattern may be summarized in the following.

After the onset of the NE monsoon in the autumn, China coastal water has been enhanced and flows southwestward. Intrusion of these cold, brackish waters into the eastern Taiwan Strait then begins, and an oceanic front with sharp salinity contrasts has been observed in the strait. It is speculated that these intruded waters originated mainly from, or at least had been strongly influenced by, the Changiang diluted water (GuAN, 1984), which is also called the Yangtze river brackish water. The speculation is based not only on the appearance of the salinity front being analogous to the outer edge of a giant river plume, but also on the vast influx of the brackish, dark green waters, which can not be supplied solely by river discharges from Fukien coast. Though some observations carried out more recently by the authors favor this opinion (we observed a giant, plume-like, brackish water tongue whose frontal edge occurred at $26^{\circ} \mathrm{N}, 121^{\circ} 20^{\prime} \mathrm{E}$ in late September 1987, then moved into the northern Taiwan Strait in November 1987), extensive surveys are still required in the future for proving such a speculation. Anyway, during the period from autumn to winter, the oceanic salinity front is quasi-stationary and evolves gradually into a temperature and salinity front. Meanwhile, under the driving of the NE monsoon, surface waters from the Kuroshio region flush into the NSCS. The existence of the quasi-stationary front in the Taiwan Strait then denotes that northerly cold waters are strong enough to stagnate the further northward movement of intruded Kuroshio waters, and the situation is favorable to the accumulation of warm Kuroshio waters in the surface layer of the NSCS. To the north of the front, currents in the eastern strait still flow mainly 


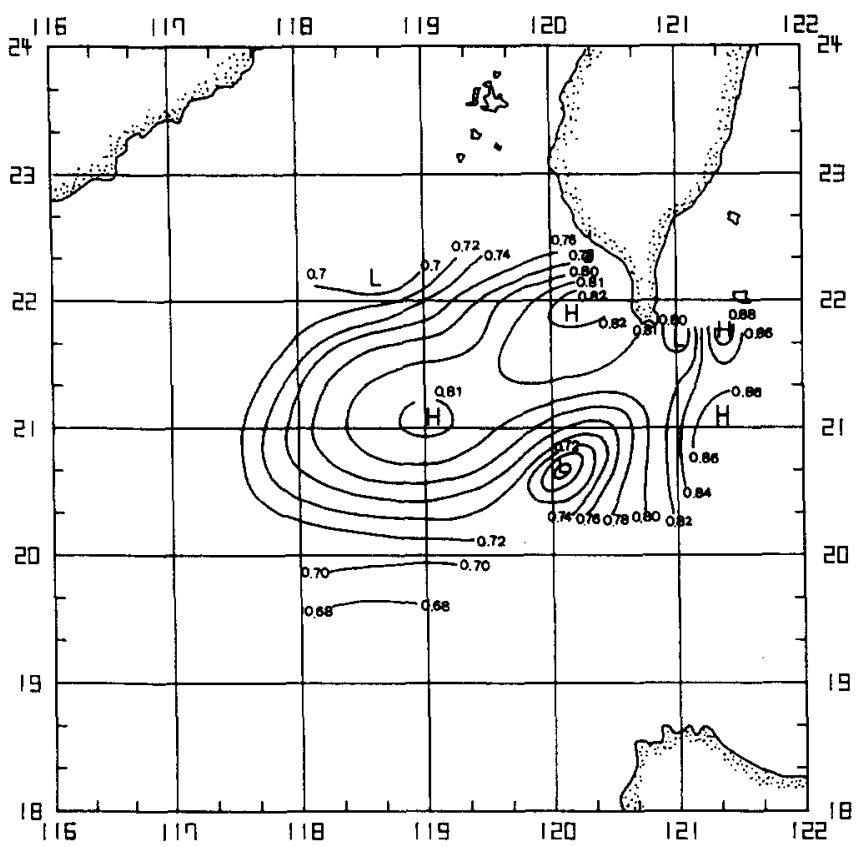

Fig. 15. Geopotential anomaly (dyn $\mathrm{m}$ ) at sea surface relative to $200 \mathrm{~m}$, showing the anti-cyclonic pattern of water flows in the NSCS, from April 13 to 19, 1985 (WANG and CHERN, 1987).

northeastward when the NE wind is weak or nonexistent, while water temperature is still low, so that the origin of these northeastward flowing waters is expected to be the China coastal current rather than that of the Kuroshio region. Since the wind-driven flows move southwestward along the China coast during the gusty winter, the northeastward movement of cold waters in the eastern strait then implies that there is possibly a cyclonic gyre of the cold waters inside the central to the northern strait when the NE wind wanes. On the other hand, due to confinements from the frontal system and nearby landmasses, wind-driven currents in the NSCS converge persistently during the NE monsoon season. Under this restriction, the intruded Pacific upper-layer warm waters will be unquestionably blocked in the NSCS, and develop eventually into an anti-cyclonic warm-core eddy there (Fig. 15).

The detail mechanism for the development of the NSCS warm-core eddy and its implications to surrounding seas have been described by WANG and CHERN (1987), and are not discussed here. However, according to this mechanism, the eddy is expected to pulsate with the variation of monsoon winds, and the frontal system in the strait acts like a check-valve for regulating the northeastward fiow. The eddy system is possibly unstable when both the density contrast across the frontal zone, which evolved with the seasonal chilling effect, becomes favorable to a warm water intrusion event and the wind stress relaxes suddenly. This situation appears usually after a strong cold-air outbreak in winter or early spring. The condition is dynamically similar to the experiment of retrieving a vertical gate which separates horizontally a heavy fluid from a relatively light one. Obviously, the role of the wind stress is dynamically analogous to the gate. Observations in the strait do show that the intrusion of southerly warm waters along the eastern coast 
of the strait always associates with these weather events (e.g. Figs 9-11). We believe that the inception of Kuroshio branch in the Taiwan Strait is triggered by such a process.

Since then, warm current intrusions occur frequently as regulated by fluctuations of $\mathrm{NE}$ monsoon winds, which then associate with the passages, or variations of the cold high pressure systems from China mainland. The salt content in the strait is therefore increased rapidly due to entrainments of intruded saline waters. This process further increases the density contrast across the frontal zone, and provides a more favorable situation for later intrusive motions than before. Sooner or later, after the seasonal warming-up and the exhaustion of recruiting cold waters, the frontal zone will stay at the western strait, and leave room in the eastern strait for the long-term penetration of warm waters from the south along the west coast of Taiwan (Fig. 5). During this stage, the originally decoupled fronts, i.e. those being interrupted by Taiwan island and located in the strait as well as the continental shelf of the East China Sea respectively, are merged together and combined into a unified frontal system. Meanwhile, a northeastward, quasi-steady current of warm Kuroshio waters appears along the eastern strait. This steady current had been observed lasting over spring and even to early summer (before the onsent of the SW monsoon) (Wang, Chern, Chen and Huang, 1987). After the seasonal transition to summer, the SCS surface water flushes into the Taiwan Strait. The Kuroshio branch is then terminated temporarily (FAN and YU, 1981; FAN, 1982).

The branching process of the Kuroshio current in both the NSCS and the Taiwan Strait is really interesting. So far, we only have limited observations in the eastern strait, from which, none the less, a gross picture of the branching of the Kuroshio had been displayed. Undoubtedly, these measurements are not sufficient enough to provide all the details we need to answer what really happens in the whole strait. They are merely representative of those in the eastern strait at best. However, since the Kuroshio branch is a phenomenon mainly restricted within the eastern strait, the inference drawn above may still be assumed to be reasonable. On the other hand, satellite IR images (e.g. Fig. 1) reveal that a small offshoot of southerly surface warm waters extend into the western strait from the north of the Penghu isles frequently during winter. In addition, recent surveys (unpublished data by the authors) also expose that, along with the appearance of a mature warm current in the eastern strait during late spring, the subsurface NSCS cold waters also upwell and extend into the Taiwan Strait along the submarine canyon (between the Penghu isles and Taiwan), then the ancestral (late Pleistocene, approximately 15,000 years ago) river valley of Minchiang (BoGGS, WANG, LEWIS and CHEN, 1976), through the northern strait to the southern East China Sea. These facts may possibly denote the importance of the bottom topographic effect on the phenomenon, and add further complexity to the interpretation of the branching process of the Kuroshio water in the Taiwan Strait. Furthermore, effects of river discharges from main estuaries along the west coast of the strait (i.e. Minchiang, Hanchiang, and even Pearl river) on the hydrography of the strait are not well-known, which may affect the branching process. The authors hope more extensive surveys, particularly in the western portion of the strait, as well as advanced studies in dynamics will be motivated from such a preliminary result in this article. Only from these future studies can details of the phenomenon be discovered.

Acknowledgements - This research was sponsored by the National Science Council of Republic of China, under contracts No. NSC76-0209-MOO2a-02, and NSC77-0209-MO02a-07. The majority of the field work was also supported by the Chinese Petroleum Corporation. 


\section{REFERENCES}

Boggs, S., JR, W. C. WANG, F. S. LewIS and J. C. ChEN (1976) Sediment properties and water characteristics of the Taiwan shelf and slope. Acta Oceanographica Taiwanica, 10, $10-49$.

CHu, T. Y. (1961) On the currents in the East China Sea and the vicinity of Taiwan. Meteorological Bulletin, 7(4), 7-17 (in Chinese).

CHU, T. Y. (1963) The oceanography of the surrounding waters of Taiwan. Report of the Institute of Fishery Biology, National Taiwan University, 1(4), 29-44 (in Chinese).

CнU, T. Y. (1971) Environmental study of the surrounding waters of Taiwan. Acta Oceanographica Taiwanica, 1, 15-32.

Csanady, G. T. (1982) Circulation in the coastal ocean. D. Reidel Pub. Comp., 279.

FAN, K. L. (1982) A study of water masses in Taiwan Strait. Acta Oceanographica Taiwanica, 13, $140-153$.

FAN, K. L. (1985) STD measurements in the seas around Taiwan during 1977-1983. Special Publication No. 44, Institute of Oceanography, National Taiwan University.

FAN, K. L. and C. Y. YU (1981) A study of water masses in the seas of southernmost Taiwan. Acta Oceanographica Taiwanica, 12, 94-111.

Guan, B. (1984) Major features of the shallow water hydrography in the East China Sea and Huanhai Sea. In: Ocean Hydrodynamics of the Japan and East China Sea, T. ICHIYE, editor, Elsevier, pp. 1-13.

HuH, L. R. (1986) Analysis of the wintertime sea-surface temperature surrounding Taiwan from satellite IR images. Master thesis, Institute of Oceanography, National Taiwan College of Marine Science and Oceanic Technology (in Chinese).

Kubokawa, A. and K. Hanawa (1984) A theory of semigeostrophic gravity waves and its application to the intrusion of a density current along a coast (part 1). Journal of the Oceanographical Society of Japan, 40, 247-259.

STERN, M. E. (1980) Geostrophic fronts, bores, breaking and blocking waves. Journal of Fluid Mechanics, 99 , $687-703$.

WANG, J. and C. S. CHERN (1985) A data report on the current and waves in the zone CBK (part 2: July 1984-March 1985). Special Publication No. 46, Institute of Oceanography, National Taiwan University (in Chinese).

WANG, J., C. S. ChERN, J. WU and J. S. CHERN (1986) A data report on the current and waves in the zone CBK (part 3: April-December, 1985). Special Publication No. 48, Institute of Oceanography, National Taiwan University (in Chinese).

WANG, J., C. S. CHERN, C. H. CHEN and Y. Y. HuANG (1987) Oceanographic observations and a diagnostic system at the CBK area. Special Publication No. 53, Institute of Oceanography, National Taiwan University (in Chinese).

WANG, J. and C. S. ChERN (1987) The warm-core eddy in the northern South China Sea. Acta Oceanographica Taiwanica, 18, 92-113 (in Chinese).

Wu, B. (1984) Some problems on circulation study in Taiwan Strait. Collected Oceanic Works, China Ocean Press, 7(1), 24-35 (in Chinese). 